\title{
REFERENCES
}

Abderhalden, E., Bloch, B. \& Rona, P. (1907). Hoppe-Seyl. Z. $52,435$.

Abderhalden, E. \& Falta, W. (1903). Hoppe-Seyl. Z. 39, 143.

Block, R. I. \& Bolling, D. (1945). The Amino-acid Composition of Proteins and Foods. Springfield, Ill.: Thomas.

Blum, L. (1908). Arch. exp. Path. Pharmak. 59, 269.

Braid, F. \& Hickmans, E. M. (1929). Arch. Dis. Childh. 4, 389.

Butts, J. S., Dunn, M. S. \& Hallman, L. F. (1938). J. biol. Chem. 123, 711.

Diaz, C. J., Mendoza, H. C. \& Rodriguez, J. S. (1939). Klin. $W s c h r .18,965$.

Embden, G. \& Baldes, K. (1913). Biochem. Z. 55, 301.

Embden, G., Salomon, H. \& Schmidt, F. (1906). Beitr. chem. Physiol. Path. 8, 129.

Falta, W. (1904). Dtsch. Arch. klin. Med. 81, 231.

Falta, W. \& Langstein, L. (1903). Hoppe-Seyl. Z. 37, 513.

Folin, O. \& Ciocalteu, V. (1927). J. biol. Chem. 73, 627.

Foster, G. L. \& Gutman, A. B. (1930). J. biol. Chem. 87, 289.

Fromherz, K. \& Hermanns, L. (1914). Hoppe-Seyl. Z. 91, 194.

Garrod, A. E. (1923). Inborn Errors of Metabolism, 2nd ed. London: Henry Froude \& Holder \& Houghton.

Glynn, L. E., Himsworth, H. P. \& Neüberger, A. (1945). Brit. J. exp. Path. 26, 326.

Guggenheim, M. (1913). Hoppe-Seyl. Z. 88, 276.

Hogben, L., Worrall, R. L. \& Zieve, I. (1932). Proc. Roy. Soc. Edinb., 52, part III, No. 13.

Katsch, G. (1918). Dtsch. Arch. klin. Med. 127, 210.

Katsch, G. (1920). Dtsch. Arch. klin. Med. 134, 59.

Katsch, G. \& Metz, E. (1927). Dtsch. Arch. klin. Med. 157, 143.

Langstein, L. \& Meyer, E. (1903). Dtsch. Arch. klin. Med. $78,161$.

Lanyar, F. (1942). Hoppe-Seyl. Z. 275, 217.

Lanyar, F. \& Lieb, H. (1931). Hoppe-Seyl. Z. 203, 135.

Leslie, A. (1943). Arch. intern. Med. 71, 68.
Levine, S. Z., Marples, E. \& Gordon, H. H. (1941). J. clin. Invest. 20, 199, 209.

Lieb, H. \& Lanyar, F. (1930). Hoppe-Seyl. Z. 186, 111.

Lorenz, E. (1937). Klin. Wschr. 16, 1463.

McCance, R. A. \& Widdowson, E. M. (1940). The Chemical Composition of Foods, Spec. Rep. Ser. Med. Res. Counc., Lond., no. 235.

Medes, G. (1932). Biochem. J. 26, 917.

Mittelbach, F. (1901). Dtsch. Arch. klin. Med. 71, 50.

Monsonyi, L. (1939). Pr. méd. 47, 708.

Moss, R. A. \& Schoenheimer, R. (1940). J. biol. Chem. 135,411 .

Neubauer, O. (1909). Dtsch. Arch. klin. Med. 95, 211.

Neubauer, O. (1928). Handb. norm. pathol. Physiol. 5, 851. Berlin: Julius Springer.

Neubauer, O. \& Falta, W. (1904). Hoppe-Seyl. Z. 42, 81.

Neuberger, A. (1947a). Biochem. J. 41, 431.

Neuberger, A. (1947b). To be published.

Neuberger, A. \& Webster, T. A. (1947). Biochem. J. 41, 449.

Papageorge, E. T., Fröhlich, M. M. \& Lewis, H. B. (1938). Proc. Soc. exp. Biol., N.Y., 38, 742.

Papageorge, E, T. \& Lewis, H. B. (1938). J. biol. Chem, 123, 211.

Penney, J. R. \& Zilva, S. S. (1945). Biochem. J. 39, 392.

Penrose, L. \& Quastel, J. H. (1937). Biochem. J. 31, 266.

Reinwein, H. (1931). Dtsch. Arch. klin. Med. 170, 327.

Roe, J. H. \& Kuether, C. A. (1943). J. biol. Chem. 147, 399.

Sachs, P. (1931). Dtsch. Arch. klin. Med. 170, 344.

Sealock, R. R., Galdston, M. \& Steele (1940). Proc. Soc. exp. Biol., N.Y., 44, 580.

Sealock, R. R., Perkinson, J. B. \& Basinski, D. H. (1941). J. biol. Chem. 140, 153.

Sealock, R. R. \& Silberstein, H. E. (1940). J. biol. Chem. $135,251$.

van Amstel, P. J. de Bruine (1910). Samml. klin: Vortr. 176-178, (562/64), 193.

Wolkow, E. \& Baumann, E. (1891). Hoppe-Seyl. Z. 15, 228.

\section{Studies on Alcaptonuria}

\section{EXPERIMENTAL ALCAPTONURIA IN RATS}

\author{
By A. NEUBERGER AND T. A. WEBSTER \\ The National Institute for Medical Research, London, N.W. 3
}

(Received 18 November 1946)

It was shown recently (Glynn, Himsworth \& Neuberger, 1945) that young albino rats reared on a diet devoid of both cystine and methionine excreted a urine which darkened on standing; incorporation of either of the two sulphur-containing amino-acids in the diet prevented the formation of this pigment or its precursor. The nature of the substance responsible

Biochem. 1947, 41 for the darkening of the urine yas not definitely established, but positive reactions for homogentisic acid were obtained. It was the primary purpose of the investigation reported in this paper to identify and isolate the substance and to determine the exact conditions which give rise to its excretion. 


\section{EXPERIMENTAL}

Animals and their general care. In the first experiment the Institute strain of black and white rats were used. Since no alcaptonuria could be produced in these rats with the diet employed, a second experiment with albino rats of the Wistar strain, supplied by Glaxo Laboratories, Ltd., was carried out: In the later experiments both black and white and albino rats bred in this Institute were used. It is not certain whether the strain of albino rats bred in this Institute is identical with that obtained from Glaxo Laboratories. In the first two experimental series littermates were distributed in the different test groups; the weights of the animals at the beginning of the experiments were between 75 and $80 \mathrm{~g}$. and their ages varied between 40 and 45 days. In the later experiments the animals used were not necessarily litter mates and their weights and ages varied more widely.

The animals were fed and housed separately; they were kept during most of the time in metabolism cages of the usual design allowing separation of urine and faeces. The receptacles for the urine contained a small quantity of $0.01 \mathrm{~N}-\mathrm{HCl}$ and toluene to prevent, as far as possible, oxidation of homogentisic acid. The volume of the urine was usually very small and the cages were washed with a constant amount of $0.01 \mathrm{~N}-\mathrm{HCl}$; urine and cage washings were combined and made up to $25 \mathrm{ml}$. The diluted urine was then filtered and portions used for the various estimations. In spite of the considerable care taken in the collection of the urines, it is believed that the recovery of the urine was never quantitative and the figures for the daily excretion of homogentisic acid given in this paper are likely to be too low. The rats were weighed three times a week and food consumption was also recorded.

Diets. The amino-acid mixtures used in the first two experimental series were very similer to those described by Glynn et al. (1945). In some of the experiments $40 \mathrm{mg}$. of $l$-phenylalanine/day was given instead of $80 \mathrm{mg}$. of the racemic compound; neither the onset nor the degree of alcaptonuria was affected by this substitution; this result agrees with the findings of Lanyar (1942) that $d$-phenylalanine produces little homogentisic acid in white rats. In the experiments of Glynn et al. (1945) $75 \mathrm{mg}$. of $\mathrm{NaHCO}_{3} /$ day was administered in order to neutralize the $\mathrm{HCl}$ derived from the hydrochlorides of the basic amino-acids supplied. This produced a neutral or even slightly alkaline urine leading to oxidation of homogentisic acid. Three of the rats were, therefore, given the basal diet without any bicarbonate, whilst the other two received the same diet as that used in the earlier work. The five rats developed alcaptonuria on the same day and the bicarbonate supplement was therefore omitted from the diets. The basal diet contained neither methionine nor cystine, whilst the cystine-supplemented diet supplied $30 \mathrm{mg}$. of that aminoacid/day. The vitamin supplements were identical with those used by Glynn et al. (1945), save that vitamin E was supplied in the form of $\alpha$-tocopherol acetate ( $0.1 \mathrm{ml}$. of a $1 \%$ solution/week). The carbohydrate-salt mixture was the same as that used in the earlier work. The 'non-protein' diet was identical with the other diets except that the amino-acid mixture was replaced by an equivalent amount of starch. Several rats were given 'tryptophan-deficient' and 'lysine-deficient' diets; the former received $1 \mathrm{~g}$. of zein supplemented with $0 \cdot 1 \mathrm{~g}$. of lysine hydrochloride and the latter $1 \mathrm{~g}$. of zein and $0.03 \mathrm{~g}$. of $l$-tryptophan/day. It was calculated that these diets provided about $0.05 \mathrm{~g}$. of tyrosine and $0.06 \mathrm{~g}$. of phenylalanine daily. The non-protein part of the diet was the same as that given to the other groups. All supplements were incorporated in the basal diet. As in the earlier experiments the intake of aminoacids or protein and of the vitamins was kept constant and the food intake was adjusted to the appetite by varying the amount of the carbohydrate-salt mixture supplied.

Chemical methods. The methods for the estimation of homogentisic acid are discussed by Neuberger (1947) and only a few details need be mentioned here. The alkali test was used in a qualitative manner and all the data given in this paper were obtained by the iodometric method. However, the molybdate method was also applied to most urine samples and gave generally good agreement with the iodometric titration. In some urines the values obtained with the colorimetric method were very much higher than those indicated by titration. This discrepancy was shown to be due to the presence of $p$-hydroxyphenylpyruvic acid which reduces the molybdate reagent but is not reversibly oxidized by iodine. Such urine specimens contained substances soluble in ether and giving a positive reaction with the Millon reagent, whilst no such substances were found in all other urines for which concordant results were obtained by the iodometric and molybdate methods respectively.

An approximate estimation of $p$-hydroxyphenylpyruvic acid was carried out in the following manner. To $5 \mathrm{ml}$. of diluted acidified urine were added $2.5 \mathrm{ml}$. of a $20 \% \mathrm{NaCl}$ solution containing $10 \% \mathrm{HCl}$. This solution was extracted three times with ethyl acetate, $5 \mathrm{ml}$. being used for each extraction. The combined extracts were washed once with $15 \mathrm{ml}$. of $0.02 \mathrm{~N}-\mathrm{HCl}$ containing $20 \% \mathrm{NaCl}$ and the keto acid was then extracted with three lots of $5 \mathrm{ml}$. each of a $0.42 \% \mathrm{NaHCO}_{3}$ solution. The bicarbonate solutions were then combined and a portion was used for the estimation of the keto acid by the Millon method as modified by Medes (1932) and by the method of Penrose \& Quastel (1937) which estimates keto acids. The results thus obtained by the two techniques agreed well; the values were also similar to those calculated from the differences of the results between the iodometric and colorimetric estimations on the urine directly.

\section{RESULTS}

The effects of feeding amino-acid mixtures deficient in sulphur to black and white rats. Five black and white rats belonging to the same litter were divided into two groups; three animals were given a diet deficient in both cystine and methionine, whilst two rats received an amino-acid mixture lacking only methionine. A sixth litter-mate was given the basal amino-acid diet supplemented by $0.08 \mathrm{~g}$. $d l$-methionine/day. Animals in both deficient groups lost weight at a fairly similar rate which averaged over the whole period about $0.75-0.95 \mathrm{~g}$./day. The weight curves fell steeply during the first week of the deficiency and then flattened out. No trace of homogentisic acid was excreted by any of the animals; on the 17th day of the experiment $40 \mathrm{mg}$. of additional $l$-phenylalanine was given to the sulphur-deficient rats and this supplement was administered for three 
successive days. No alcaptonuria developed. After 42-45 days the animals were killed; the rats on the deficient diets which had been weighing between 80 and $83 \mathrm{~g}$. at the beginning of the experiment had by then lost between 37 and $41 \mathrm{~g}$. Their organs, particularly the livers, were examined both macroscopically and histologically. There was no evidence of necrosis. The one rat on the diet containing methionine grew at a rate of about $2 \mathrm{~g}$./day; it was killed after 30 days and no abnormalities were found.

\section{The effects of cystine and methionine deficiency on albino rats}

General symptoms. Since the earlier experiments of Glynn et al. (1945), in which alcaptonuria and necrosis were observed were done on albino rats, it was thought desirable to repeat this work with rats of that strain. Wistar rats (Glaxo Laboratories, Ltd.), all litter-mates, were therefore divided into two groups; animals G 1, G 2, G 4, G 5 and G 8 received the basal diet only which was almost free of methionine and cystine, whilst the animals $G 6$ and G 7 received the basal diet supplemented with cystine (30 mg./day). The animals in both groups lost weight rapidly (Table 1), though it appeared that

Table 1. Weight changes and date of appearance of alcaptonuria of rats receiving a diet deficient in both cystine and methionine $(A)$ and of rats receiving a diet deficient in methionine only $(B)$

\begin{tabular}{|c|c|c|c|c|}
\hline $\begin{array}{c}\text { No. } \\
\text { and sex } \\
\text { of rat }\end{array}$ & Diet & $\begin{array}{l}\text { Weight } \\
\text { at the } \\
\text { beginning } \\
\text { of the } \\
\text { experiment } \\
\text { (g.) }\end{array}$ & $\begin{array}{c}\text { Loss of } \\
\text { weight } \\
\text { during } \\
\text { first } \\
30 \text { days } \\
\text { (g.) }\end{array}$ & $\begin{array}{l}\text { First } \\
\text { appearance } \\
\text { of homo- } \\
\text { gentisic } \\
\text { acid in } \\
\text { the urine } \\
\text { (days) }\end{array}$ \\
\hline $\begin{array}{lll}\text { G } & 1 & 0 \\
\text { G } & 2 & 0 \\
\text { G } & 4 & 0 \\
\text { G } & 5 & 9 \\
\text { G } & 8 & 0 \\
\text { G } & 6 & 0 \\
\text { G } & 7 & 0\end{array}$ & $\begin{array}{l}\mathbf{A} \\
\mathbf{A} \\
\mathbf{A} \\
\mathbf{A} \\
\mathbf{A} \\
\mathbf{B} \\
\mathbf{B}\end{array}$ & $\begin{array}{l}76 \\
75 \\
78 \\
79 \\
77 \\
77 \\
75\end{array}$ & $\begin{array}{l}29 \\
30 \\
31 \\
31 \\
27 \\
22 \\
24\end{array}$ & $\begin{array}{l}14 \\
12 \\
15 \\
12 \\
11 \\
-\end{array}$ \\
\hline
\end{tabular}

the rate of this decrease in weight was slower in the rats receiving cystine than in the other animals reared on the basal diet alone. During the first two weeks of the experiments there were no obvious signs of nutritional deficiency, apart from loss of weight. Later, however, the animals lost their hair and during the last days of the experiment many of the animals were ill and some were killed when obviously dying. Apart from the symptoms of wasting, such as almost complete disappearance of depot fat, no gross abnormalities were found. There was no definite evidence of necrosis of the liver in any of the animals. Parts of the livers of the animals used in this and the first experiment were taken for the estimation of glutathione. The results of these deter- minations are reported in a separate paper (Leaf \& Neuberger, 1947).

Onset of alcaptonuria. This occurred at almost exactly the same time in all the five animals of the first group (Table 1). The daily excretion of homogentisic acid on the basal diet alone varied considerably from day to day even in the same animal. It

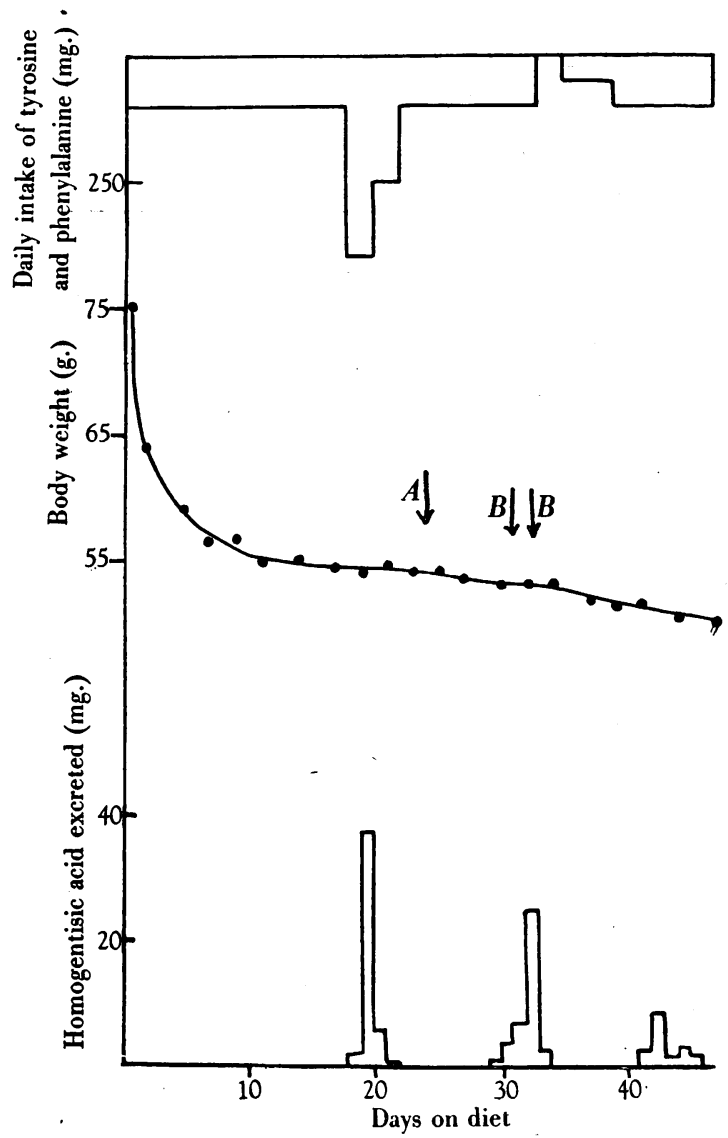

Fig. 1. The effect of cystine on the excretion of homogentisic acid of rat $G$ 7. The animal received $0.03 \mathrm{~g}$. $l$-cystine/day from the beginning of the experiment. On the 24th day $(A \downarrow)$ cystine was left out of the diet. On the 31st and 32nd day $0.06 \mathrm{~g}$. homogentisic acid/day was given $(B \downarrow)$. The supplements to the basal diet indicated in the top of the graph consisted of $l$-tyrosine.

was usually between 5 and $10 \mathrm{mg}$., but values as low as $0.5 \mathrm{mg}$. and as high as $15 \mathrm{mg}$. were occasionally found. When no extra aromatic amino-acids were fed, it was found that only about $6-10 \%$ of the tyrosine and phenylalanine present in the diet were converted to homogentisic acid and this proportion did not increase significantly during the experiment. Complete removal of either tyrosine or phenylalanine from the diet led to a complete disappearance of the alcaptonuria (Figs. 1 and 2). Increasing 
the intake of phenylalanine or tyrosine led to a considerable absolute and relative rise of excretion of homogentisic acid. With higher levels of intake, particularly of $l$-phenylalanine, the rate of conversion to homogentisic acid approached almost $50 \%$ (Fig. 3).

Effect of the administration of cystine on alcaptonuria. When cystine was given from the beginning of the experiment no alcaptonuria developed (Figs. 1 and 2) unless the intake of aromatic amino-acids was substantially raised. These findings agree with those reported by Glynn et al. (1945) who did not find any

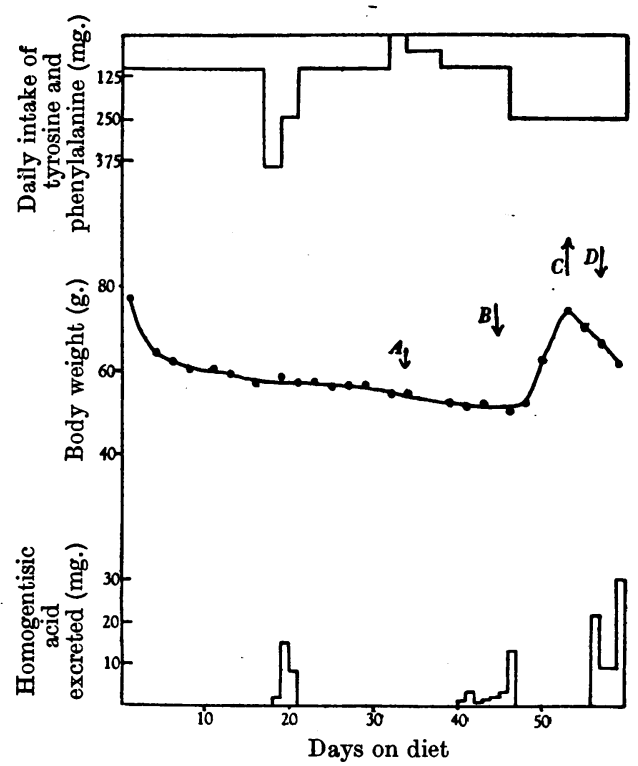

Fig. 2. The effect of cystine and methionine on the excretion of homogentisic acid of rat $G 6$. This rat received $0.03 \mathrm{~g}$. $l$-cystine/day from the beginning of the experiment; $A \downarrow$ indicates termination of cystine supplement. $B \downarrow$ indicates addition of $0.08 \mathrm{~g}$. $d l$-methionine/day. This was again removed from the diet after 6 days $(C \uparrow \uparrow)$. $l$-Cystine $(0.08 \mathrm{~g}$./day) was added 4 days later $(D \downarrow)$. Amino-acid supplement consisted of $l$-tyrosine.

evidence of alcaptonuria in rats receiving cystine but no methionine for periods of up to 147 days. When rats $G 6$ and $G 7$ which had been on the methioninedeficient diet for 19 days, were given $0.3 \mathrm{~g}$. of extra tyrosine for three successive days, they promptly excreted homogentisic acid (Figs. 1 and 2). Reduction of the tyrosine intake produced a corresponding decrease in the excretion of homogentisic acid and the alcaptonuria again disappeared, when the animals were returned to the basal diet containing $100 \mathrm{mg}$. of aromatic amino-acids (Figs. 1 and 2). Removal of cystine from this diet produced alcaptonuria within a week, although the intake of tyrosine and phenylalanine had not been increased during that period (Figs. 1 and 2).
The administration of cystine to rats which had developed alcaptonuria on the cystine-free basal diet produced equivocal results. In several experiments the excretion of homogentisic acid appeared to be significantly reduced (Fig. 4), in others no definite change was observed (Fig. 5). Similar results were obtained with cysteine (Figs. 4 and 5).

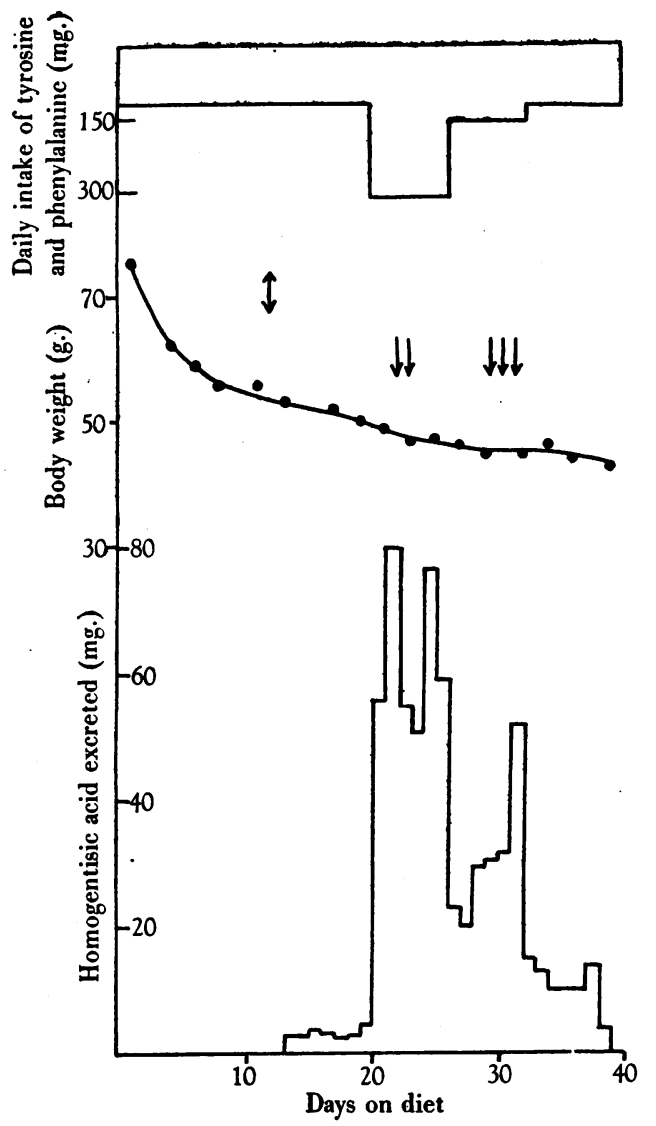

Fig. 3. The effect of ascorbic acid and $l$-phenylalanine on the excretion of homogentisic acid of rat $\mathrm{G} 2$. This rat received no cystine in its basal diet. The variations in the intake of aromatic amino-acids were produced by additions of $l$-phenylalanine. The double-headed arrow indicates the first appearance of homogentisic acid in the urine. All other arrows indicate administration of $l$ ascorbic acid (0.03 g./day). Supplements consisted of $l$-tyrosine.

Effect of the administration of methionine on alcaptonuria. When $0.08 \mathrm{~g}$. of $d l$-methionine/day was given to animals which had been on the basal diet alone or on the basal diet supplemented with cystine, resumption of growth occurred in a dramatic fashion. The animals gained about $4 \mathrm{~g}$./day and doubled their weight in about 12 days. Alcaptonuria disappeared within $24 \mathrm{hr}$. of the giving of methionine 
(Fig. 5) and even a greatly increased intake of tyrosine was well tolerated. Indeed, a total daily intake of $0.5 \mathrm{~g}$. of aromatic amino-acids failed to produce alcaptonuria. When after a period of methionine administration this amino-acid was again removed from the diet, alcaptonuria reappeared after an interval of a few days, i.e. much sooner than was found at the beginning of the experiment (Fig. 2).

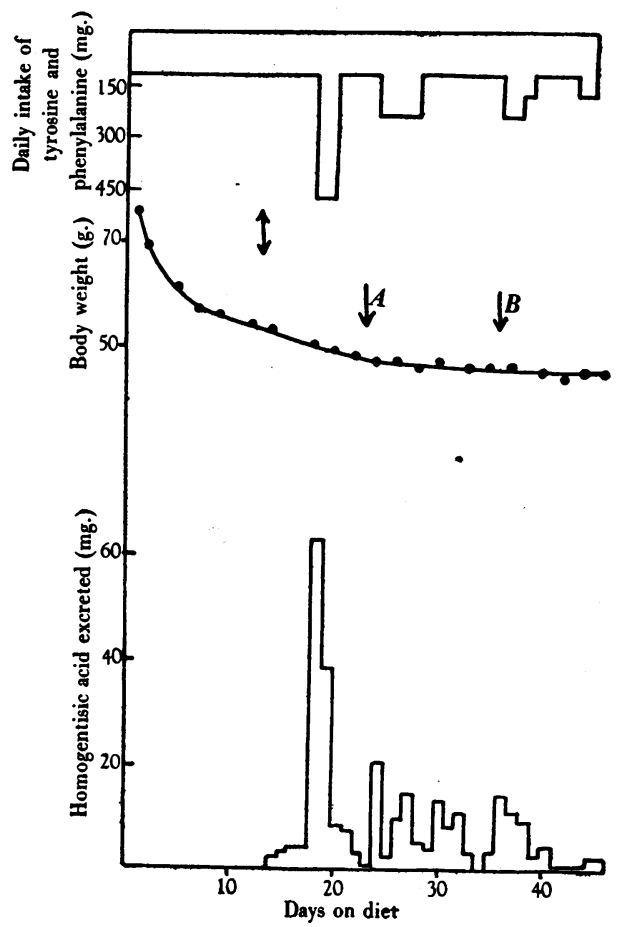

Fig. 4. The effect of cystine and cysteine on the excretion of homogentisic acid of rat $\mathrm{G} 4$. This rat had received no cystine in its basal diet. $A \downarrow$ indicates administration of $l$-cystine $(0.06 \mathrm{~g}$./day). Later $(B \downarrow)$ this was replaced by $l$-cysteine hydrochloride $(0 \cdot 1 \mathrm{~g}$./day). The double-headed arrow indicates onset of alcaptonuria. Amino-acid supplements consisted of $l$-tyrosine.

Effect of ascorbic acid on alcaptonuria. Since scorbutic guinea-pigs excrete homogentisic acid in addition to $p$-hydroxyphenylpyruvic acid in the urine on administration of tyrosine, it was thought possible that the alcaptonuria observed in methionine and cystine-deficient rats might be caused by an interference with the synthesis of this vitamin by the amino-acid deficiency. Figs. 3 and 6 show that administration of ascorbic acid has no demonstrable effect on the excretion of homogentisic acid.

Effect of aromatic keto acids on the output of homogentisic acid. It has already been pointed out that addition of tyrosine and phenylalanine increases homogentisic acid excretion; the corresponding keto acids were found to have similar effects (Fig. 6).

Isolation of homogentisic acid. Acidified, diluted rat urine $(300 \mathrm{ml}$.) estimated to contain about $0.9 \mathrm{~g}$. of homogentisic acid, was extracted with ether in a liquid extractor for $48 \mathrm{hr}$. The dried ether was concentrated to about $10 \mathrm{ml}$. and extracted with $30 \mathrm{ml}$. of water in three equal portions; lead acetate trihydrate $(5 \mathrm{~g}$.$) dissolved in water (25 \mathrm{ml}$.) was

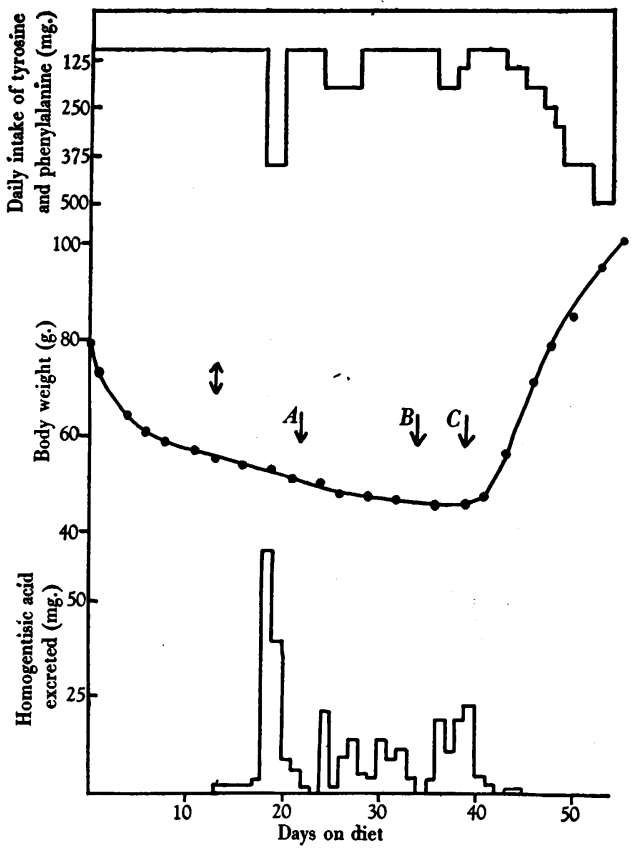

Fig. 5. Comparison of the effect of cystine, cysteine and methionine on the output of homogentisic acid in a rat (G 4) which had no cystine in its basal diet. The doubleheaded arrow indicates onset of alcaptonuria. Arrows marked $A, B$ and $C$ indicate periods of administration of $l$-cystine $(0.06 \mathrm{~g} . /$ day $), l$-cysteine $(0.1 \mathrm{~g}$./day) and $d l$ methionine $(0.08 \mathrm{~g}$./day) respectively. Variations of intake of aromatic amino-acids were produced by administration of $l$-tyrosine.

then added at about $80^{\circ}$. The material which crystallized on cooling was filtered off, recrystallized from hot water and air-dried. It amounted to $0.95 \mathrm{~g}$. and had m.p. $215^{\circ}$. (Found: C, 32.0; $\mathrm{H}, 3 \cdot 2 ; \mathrm{PbO}, 37 \cdot 5$. Calc. for $\mathrm{C}_{16} \mathrm{H}_{14} \mathrm{O}_{8} \mathrm{~Pb} .3 \mathrm{H}_{2} \mathrm{O}: \mathrm{C}$, $32.3 ; \mathrm{H}, 3.36$; $\mathrm{PbO}, 37.5 \%$.) Of the material $120 \mathrm{mg}$. were dried in vacuo over $\mathrm{P}_{2} \mathrm{O}_{5}$ at $80^{\circ}$; loss of weight found was $10.7 \mathrm{mg}$. (calc. for the trihydrate $10.9 \mathrm{mg}$.). The properties agree fully with those described for the lead salt of homogentisic acid by Wolkow \& Baumann (1891). The lead salt (300 mg.) was converted into free homogentisic acid by $\mathrm{H}_{2} \mathrm{~S}$; the acid was recrystallized from ether and chloroform and had m.p. $146^{\circ}$. There was no depression of m.p., when a sample of this material was mixed with a sample of synthetic homogentisic acid. 
Excretion of p-hydroxyphenylpyruvic acid. Administration of large doses of extra tyrosine to some of the rats on sulphur-deficient diets gave rise to excretion of $p$-hydroxyphenylpyruvic acid (Figs. 4 and 5). Thus, when rat $G 1$ received $0.3 \mathrm{~g}$. of extra

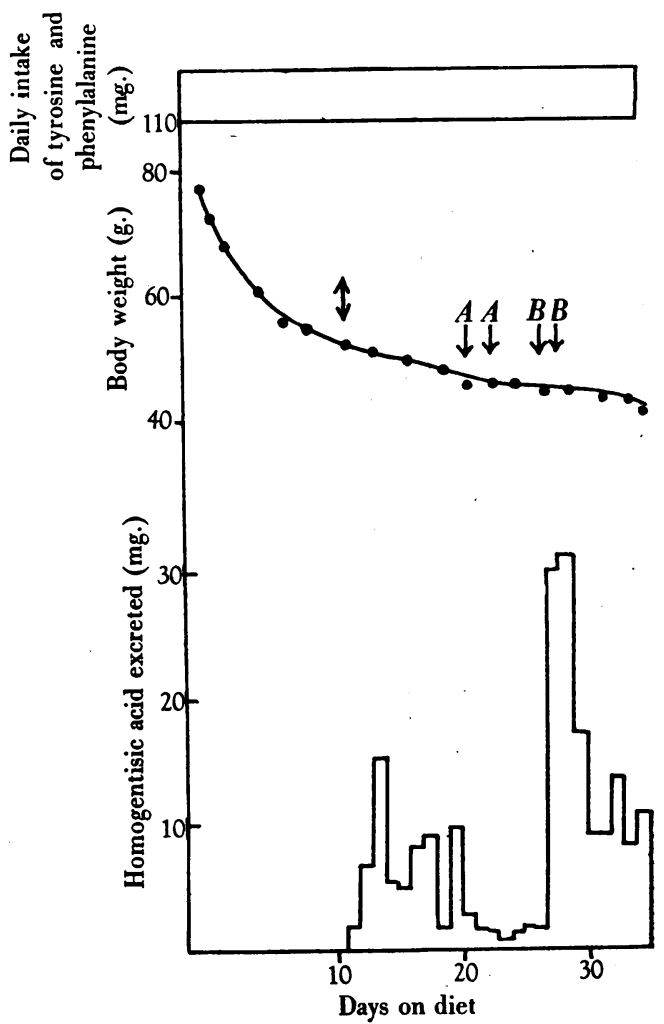

Fig. 6. Effect of ascorbic acid and phenylpyruvic acid on the output of homogentisic acid of rat $G$. The doubleheaded arrow indicates onset of alcaptonuria. Arrows marked $A$ indicate administration of $l$-ascorbic acid $(0.01 \mathrm{~g} . /$ day $)$, whilst arrows marked $B$ indicate administration of phenylpyruvic acid (0.05 g./day).

tyrosine on two successive days, the differences between the iodometric and colorimetric values for homogentisic acid indicated amounts of the keto acids of 21 and $32 \mathrm{mg}$. respectively. Estimations by the Millon method gave values for the two days of 21 and $29 \mathrm{mg}$. The acid was not isolated, but there is little doubt that it was $p$-hydroxyphenylpyruvic acid, for the following reasons. The substance was found to be acidic and was soluble in water, ether and ethyl acetate. It reduced molybdate in acid solution, but did not react reversibly with iodine. The acid also reacted both with Millon's reagent and 2:4-dinitrophenylhydrazine. The fact that similar values were obtained by three different methods of estimation indicated the absence of hydroxyphenyllactic acid.
Production of alcaptonuria in albino and black and white rats by a protein-deficient diet. The experiments so far described showed that albino rats kept on a diet deficient in methionine and cystine excreted homogentisic acid, though the intake of aromatic amino-acids was low. The question arose whether this increased susceptibility to alcaptonuria could also be induced by a diet deficient in protein. Six rats, three of the albino strain of the Institute, and three of the black and white strain, with initial weights of 85-101 g., were put on the protein-deficient diet. After 3 weeks their weights had dropped to about $70 \mathrm{~g}$. ; they were then given varying amounts of tyrosine, but no other amino-acids. After an interval of 1 or 2 days rats of both strains excreted homogentisic acid. With a daily intake of $0.3 \mathrm{~g}$. of tyrosine the daily output of homogentisic acid varied between 30 and $80 \mathrm{mg}$.; when the daily dose of tyrosine was reduced to $0 \cdot 2 \mathrm{~g}$. homogentisic acid was between 6 and $25 \mathrm{mg}$./day and a further reduction of tyrosine to $0 \cdot 1 \mathrm{~g}$. abolished alcaptonuria altogether in most rats. There was no obvious difference between the two strains. Addition of $0.08 \mathrm{~g}$. of $d l$ methionine or of $0.06 \mathrm{~g}$. of $l$-cystine to the daily ration had no significant effect on the degree of alcaptonuria observed.

Alcaptonuria and deficiency of lysine and tryptophan. Albino rats weighing between 70 and $80 \mathrm{~g}$. were put on zein diets supplemented with lysine hydrochloride and tryptophan respectively. After 3 weeks on the deficient diet they had lost between 15 and 20 g.; they did not excrete any homogentisic acid. Various quantities of tyrosine were now added to their diets and the results of two typical experiments are shown (Tables 2 and 3). It was found that lysine-deficient rats did not excrete homogentisic acid in significant amounts, unless their intake of additional tyrosine, apart from that contained in the basal diet, was about 0.1 g./day. The tryptophandeficient rats showed alcaptonuria already with a dose of additional tyrosine of $0.05 \mathrm{~g}$. With $0.2 \mathrm{~g}$. of tyrosine the alcaptonuria was very marked in all deficient animals. Neither the addition of cystine nor that of methionine had any effect on the output of homogentisic acid. Supplementation of the lysine and tryptophan-deficient diets with the lacking amino-acid abolished the alcaptonuria in a few days, if the intake of extra tyrosine was kept at the level of $0.15 \mathrm{~g}$. or less. With larger doses of tyrosine, however, the effect of the supplementation was less marked, at least during the comparatively short period of 6 days employed. It is likely that this was due to the fact that zein, even if it is supplemented with lysine and tryptophan, is still quantitatively deficient in several essential amino-acids. When zein was replaced by casein, the alcaptonuria disappeared even with an extra tyrosine intake of $0 \cdot 3 \mathrm{~g} . /$ day. 
Table 2. Lysine deficiency and alcaptonuria

(The two albino rats weighed 70 and $68 \mathrm{~g}$. respectively at the beginning of the experiment. They had been on the deficient diet for 24 days without showing alcaptonuria. Additional tyrosine was then given.)

\begin{tabular}{|c|c|c|c|}
\hline & Date & Supplement & $\begin{array}{l}\text { acid excreted } \\
\text { (mg.) }\end{array}$ \\
\hline \multirow[t]{12}{*}{ 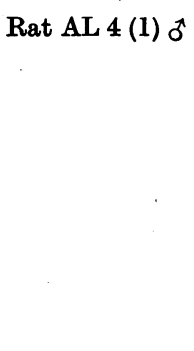 } & 14. vii & 0.05 g. $l$-tyrosine & 0 \\
\hline & 15. vii & \multirow{2}{*}{$"$} & 0 \\
\hline & 16. vii & & 0 \\
\hline & 17. vii & $0.1 \mathrm{~g} \cdot l$-tyrosine & 5.0 \\
\hline & 18. vii & 0.15 g. $\ddot{l}$-tyrosine & 0.5 \\
\hline & 19. vii & $0 \cdot 15$ g. $l$-tyrosine & $4 \cdot 5$ \\
\hline & 20. vii & , & $\mathbf{3 . 5}$ \\
\hline & 21. vii & $0 \cdot 2$ g. $l$-tyrosine & $17 \cdot 0$ \\
\hline & 22. vii & \multirow{2}{*}{$0.2 \mathrm{~g} \cdot l$-tyrosine $+0.075 \mathrm{~g} . l$-lysine $\mathrm{HCl}$} & $19 \cdot 0$ \\
\hline & 23. vii & & $40 \cdot 0$ \\
\hline & 24. vii & " $\quad "$ & $18 \cdot 0$ \\
\hline & 25. vii & ", & $\mathbf{0}$ \\
\hline \multirow[t]{9}{*}{ Rat $\mathrm{AL} 4(2){ }^{\star}$} & 14. vii & $0.1 \mathrm{~g} \cdot l$-tyrosine & 0 \\
\hline & 15. vii & 2 - 0.0 & $8 \cdot 4$ \\
\hline & 16. vii & $"$ & $19 \cdot 3$ \\
\hline & 17. vii & $"$ & $4 \cdot 3$ \\
\hline & 18. vii & & $7 \cdot 5$ \\
\hline & 19. vii & \multirow{2}{*}{$\begin{array}{l}0.15 \mathrm{~g} \cdot l \text {-tyrosine } \\
0.2 \mathrm{~g} \cdot l \text {-tyrosine }+0.1 \mathrm{~g} \cdot l \text {-cystine }\end{array}$} & $35 \cdot 9$ \\
\hline & 22. vii & & $83 \cdot 2$ \\
\hline & 23. vii & " & $63 \cdot 0$ \\
\hline & 24. vii & $"$ & $82 \cdot 0$ \\
\hline
\end{tabular}

Table 3. Tryptophan deficiency. and alcaptonuria

(The two albino rats had been on the tryptophan-deficient diet for 21 days before tyrosine was given. Their initial weights were 86 and $83 \mathrm{~g}$. respectively.)

\begin{tabular}{|c|c|c|c|}
\hline & Date & Supplement & (mg.) \\
\hline \multirow[t]{9}{*}{ Rat AL 5 (1) } & 14. vi & $0.05 \mathrm{~g} \cdot l$-tyrosine & $33 \cdot 0$ \\
\hline & 15. vi & , & $20 \cdot 0$ \\
\hline & 16. vi & , & $7 \cdot 0$ \\
\hline & 17. vi & $0 \cdot 1$ g. $l$-tyrosine & $40 \cdot 0$ \\
\hline & 18. vi & $0.1 \mathrm{~g} . l$-tyrosine $+0.025 \mathrm{~g} . l$-tryptophan & $37 \cdot 2$ \\
\hline & 19. vi & " $\quad "$, & $28 \cdot 8$ \\
\hline & 20. vi & ” & $26 \cdot 7$ \\
\hline & 21. vi & , & 0 \\
\hline & 22. vi & $"$ & 0 \\
\hline \multirow[t]{7}{*}{ Rat AL 5 (6) } & 14. vi & $0 \cdot 1$ g. $l$-tyrosine & $10 \cdot 6$ \\
\hline & 15. vi & " & $24 \cdot 0$ \\
\hline & 16. bi & \multirow{2}{*}{ " } & $30 \cdot 0$ \\
\hline & 17. vi & & $42 \cdot 2$ \\
\hline & 18. vi & $0.1 \mathrm{~g} . l$-tyrosine $+0.1 \mathrm{~g} . l$-cystine & $26 \cdot 7$ \\
\hline & 19. vi & " & $35 \cdot 7$ \\
\hline & 20. vi & $"$ & $74 \cdot 0$ \\
\hline
\end{tabular}

\section{DISCUSSION}

The isolation of homogentisic acid from the urine of albino rats receiving a diet deficient in both cystine and methionine shows that the blackening of the urine observed in the experiments of Glynn et al. (1945) was due to alcaptonuria. It is of some interest that excretion of homogentisic acid could be consistently produced in animals which obtained only $65 \mathrm{mg}$. of tyrosine and $40 \mathrm{mg}$. of phenylalanine/day, amounts which would be present in any normal diet supplied to rats of that age. It was found that only a small fraction of the ingested aromatic amino-acids was excreted in the urine in the form of homogentisic acid and this proportion increased greatly with rising intake of tyrosine or phenylalanine. Unlike. congenital human alcaptonuria, the metabolic lesion produced in rats by this amino-acid deficiency does not involve a complete blockage of the intermediary metabolism of the two aromatic amino-acids. With moderate intakes of tyrosine, homogentisic acid appeared to be the only aromatic metabolite present in the urine in abnormal quantities; only when large amounts of tyrosine were administered was $p$ hydroxyphenylpyruvic acid excreted in measurable amounts. This type of alcaptonuria produced in rats 
differs, therefore, from the metabolic disturbances described in premature infants (Levine, Marples \& Gordon, 1941) and those occurring in guinea-pigs (Sealock \& Silberstein, 1940). Both these conditions are caused by a dietary deficiency in vitamin $\mathbf{C}$ and are associated with the excretion of large amounts of $p$-hydroxyphenylpyruvic acid. The alcaptonuria described here is not affected by the administration of ascorbic acid and the differences in excretion products observed may be either due to the fact that various species behave in a different manner or that the metabolic lesion involved varies with the dietary deficiency producing it.

No alcaptonuria could be produced in black and white rats with the sulphur-deficient diet. This might indicate genetic differences between the two strains. However, with a protein-deficient diet and a large intake of tyrosine, black and white rats excreted homogentisic aeid in amounts not significantly smaller than those found with albino rats. It is concluded therefore that such a difference between the two strains, if it really exists, is only relative.

When this alcaptonuria was first discovered, it was thought to be due specifically to a deficiency in sulphur-containing amino-acid. This interpretation, however, is not borne out by the present experiments. Alcaptonuria can be produced in white rats receiving a normal diet, if large quantities of $l$ phenylalanine are administered. This was first shown by Papageorge \& Lewis (1938) and has been confirmed by various workers (Butts, Dunn \& Hallman, 1938; Closs \& Braaten, 1941; Abbott \& Salmon, 1943; Lanyar, 1943). l-Tyrosine has also been shown effective in this respect (Butts, Sinnhuber \& Dunn, 1941) and this has been confirmed by other workers. Strangely enough Martin \& Hueper (1943) found that their rats, which were fed on diets containing large quantities of tyrosine for several weeks, did not excrete homogentisic acid. This type of alcaptonuria has generally been found not to appear at once and the interval between the administration of the 'extra' amino-acid and the appearance of alcaptonuria is reduced as the dose is increased. It is possible that the inability of the body to metabolize the aromatic amino-acids in a normal manner is, at least partly, caused by the toxic effect of excessive tyrosine, which is either 'supplied as such or produced in the body from the administered phenylalanine. The dose necessary to produce alcaptonuria was found by most workers to be about $0.4-0.5 \mathrm{~g}$. of amino-acid/100 g. of body weight; or, if the amino-acids given in the basal diet are included, about $0.6 \mathrm{~g}$. Our own unpublished observations also indicate that it is necessary to supply at least $0.65 \mathrm{~g}$. of aromatic amino-acids/ $100 \mathrm{~g}$. of body weight in order to produce alcaptonuria within a week in the majority of animals given a diet containing $15 \%$ of casein. Whether such a linear correlation between minimal dose and body weight really exists is uncertain, and in view of the considerable individual variations in animals a very large number of experiments would have to be done before this point could be considered established. However, with normal animals of very different weights, we have never been able to produce alcaptonuria unless the total intake of aromatic aminoacids was at least $0.5 \mathrm{~g} . / 100 \mathrm{~g}$. of body weight and this agrees with the findings of other workers.

The alcaptonuria observed in sulphur-deficient rats already appears, where the total intake of the two aromatic amino-acids is about $0.1 \mathrm{~g} . /$ day or $0.15 \mathrm{~g} . / 100 \mathrm{~g}$. of body weight. It follows therefore that the decreased capacity of these animals to metabolize tyrosine and phenylalanine in a normal manner, can only partially be explained by the reduction in body weight associated with the dietary deficiency. This is also clearly shown in the experiments in which addition of methionine to a sulphurdeficient diet raised the tolerance to tyrosine quite out of proportion to the increase in weight. It appears that even if the change of weight is taken into account, deficiency of methionine and cystine reduces the minimal dose of aromatic amino-acids necessary to produce alcaptonuria to about a fourth of that found with animals on a normal diet. The results reported here also indicate that this effect is not specifically associated with a deficiency of one particular amino-acid. Thus the administration of cystine or methionine to rats receiving $200 \mathrm{mg}$. of tyrosine in addition to a protein-deficient diet, does not. reduce the excretion of homogentisic acid observed under such conditions. Moreover, the observation that the addition of 50 or $100 \mathrm{mg}$. of tyrosine to diets deficient in tryptophan and lysine respectively produces alcaptonuria, suggests that any deficiency of an essential amino-acid leads to a decreased ability of the animal to break down aromatic amino-acids in a normal manner. The total intake of aromatic amino-acids/100 $\mathrm{g}$. of body weight for animals just showing alcaptonuria was about $220 \mathrm{mg}$. for tryptophan deficiency and about $300 \mathrm{mg}$. for lysine deficiency. All these observations are compatible with the assumption that any deficiency of an essential amino-acid reduces the level of intake of tyrosine and phenylalanine necessary to produce alcaptonuria, and that the differences observed with the various diets are those of degree rather than of kind. When both methionine and cystine are lacking in the diet, alcaptonuria occurs even when only 'normal' amounts of tyrosine and phenylalanine are present in the diet. If cystine is supplied and the deficiency is confined to methionine, the intake of aromatic amino-acids has to be somewhat increased, before homogentisic acid is excreted; a deficiency of tryptophan appears to have similar effects to that of methionine, whilst lack of lysine 
interferes with the metabolism of aromatic aminoacids to a lesser extent. Whether any deficiency of an essential metabolite will have similar effects must remain a matter for further investigation.

Closs \& Braaten (1941) in their investigations on the metabolism of large doses of $l$-phenylalanine in rats, found that the nature of the excretion product was influenced by the acid-base balance of the organism and that homogentisic acid is only excreted if alkali is administered together with the amino-acid. A somewhat similar effect on the reduction of the output of homogentisic acid in scorbutic guinea pigs by acidic substances was reported by Sealock (1942). We have therefore given some attention to the $\mathrm{pH}$ of the urines of the rats on aminoacid diets. Alcaptonuria was observed at about the same time in animals receiving bicarbonate and excreting a neutral or alkaline urine as in animals which had not been supplied with bicarbonate to neutralize amino-acid hydrochlorides, and which excreted a urine of a $\mathrm{pH}$ of about 4.8. As reported above, in the later phases of the experiment no alkali was given and it is concluded therefore that alkalosis need not be considered in the interpretation of these results.

The sulphur-deficient diets employed in this work have been used by Glynn et al. (1945) to produce massive hepatic necrosis, and the failure to repeat these results calls for an explanation. It is probable that animals on a diet completely deficient in methionine and cystine are less susceptible to liver damage than rats receiving very small amounts of a sulphur-containing amino-acid; this is suggested by the results of Himsworth \& Glynn (1944) who found that diets containing 4-6\% of casein are more likely to produce necrosis than diets with no protein or diets containing only $2 \%$ of casein. It was also found (Glynn et al. 1945) that necrosis was more easily produced in rats given $8 \mathrm{mg}$. of methionine/ day than in animals receiving no amino-acid sulphur. Moreover, the animals on the sulphur-de- ficient diet used in this work lost weight very rapidly and appeared to die of inanition before necrosis could develop. It is also possible that the tocopherol which was given in our experiments, but not by Glynn et al. (1945) had some protective effect; this is suggested by the results of Schwarz (1944) who found that tocopherol protected rats against liver necrosis produced by an unknown factor. Data at present available do not permit us to decide which of these explanations is correct and it can only be stated that, in spite of the large amount of work done on this subject, we are still ignorant of the exact conditions required for the production of hepatic necrosis and exactly how the diet affects and facilitates liver damage.

\section{SUMMARY}

1. Homogentisic acid has been isolated from the urine of rats fed a diet deficient in męthionine and cystine and containing only relatively small amounts of tyrosine and phenylalanine. If cystine was added to such a diet, no alcaptonuria occurred, unless the tyrosine intake was also raised. When large amounts of tyrosine were administered, some $p$-hydroxyphenylpyruvic acid was also excreted.

2. Alcaptonuria was also produced if tyrosine was added to a protein-deficient diet. The excretion of homogentisic acid occurring under these conditions was not affected by the administration of cystine or methionine.

3. It was found that the threshold of the intake of phenylalanine and tyrosine necessary to produce alcaptonuria was significantly reduced by a deficiency of tryptophan and, to a lesser extent, by a lack of lysine. It is suggested that any deficiency of an essential amino-acid may impair the capacity of the organism to deal in a normal manner with the two aromatic amino-acids.

4. No hepatic lesions were found in any of the animals. Possible reasons for such negative findings are discussed.

\section{REFERENCES}

Abbott, L. D. \& Salmon, C. L. (1943). J. biol. Chem. 150, 339.

Butts, J. S., Dunn; M. S. \& Hallman, L. F. (1938). J. biol. Chem. 123, 711.

Butts, J. S., Sinnhuber, R. O. \& Dunn, M. S. (1941). J. biol. Chem. 140, xxii.

Closs, K. \& Braaten, K. (1941). Hoppe-Seyl. Z. 271, 221.

Glynn, L. E., Himsworth, H. P. \& Neuberger, A. (1945). Brit. J. exp. Path. 26, 326.

Himsworth, H. P. \& Glynn, L. E. (1944). Clin. Sci. $5,93$.

Lanyar, F. (1942). Hoppe-Seyl. Z. 275, 217.

Lanyar, F. (1943). Hoppe-Seyl. Z. 278, 155.

Leaf, G. \& Neuberger, A. (1947). Biochem. J. 41, 280.
Levine, S. Z., Marples, E. \& Gordon, H. H. (1941). J. clin. Invest. 20, 199, 209.

Martin, G. I. \& Hueper, W. C. (1943). Arch. Biochem. 1, 435.

Medes, G. (1932). Biochem. J. 26, 917.

Neuberger, A. (1947). Biochem. J. 41, 431.

Papageorge, E. \& Lewis, H. B. (1938). J. biol. Chem. 123, 211.

Penrose, L. \& Quastel, J. H. (1937). Biochem. J. 31, 266.

Schwarz, K. C. (1944). Hoppe-Seyl. Z. 281, 101, 109. .

Sealock, R. R. (1942). J. biol. Chem. 146, 503.

Sealock, R. R. \& Silberstein, H. E. (1940). J. biol. Chem. 135, 251.

Wolkow, E. \& Baumann, E. (1891). Hoppe-Seyl. Z. 15, 228. 